\author{
Arundhati Bag $^{1 \star}$, Lalit Mohan Jeena ${ }^{2}$ \\ and Niladri $\mathrm{Bag}^{3}$ \\ ${ }^{1}$ PhD, Assistant Professor, Department of Medical \\ Biotechnology, Sikkim Manipal University, Sikkim \\ 737102, India \\ ${ }^{2} M S c$, SRF, IVRI, Bareily, Uttar Pradesh, India \\ ${ }^{3} \mathrm{PhD}$, Assistant Professor, Horticulture Department, \\ Sikkim University, Sikkim 737102, India \\ Dates: Received: 22 March, 2014; Accepted: 05 \\ January, 2015; Published: 07 January, 2015 \\ *Corresponding author: Dr. Arundhati Bag, \\ PhD, Assistant Professor, Department of Medical \\ Biotechnology, Sikkim Manipal University, Sikkim \\ 737102, India, Tel: 08900528657; E- mail: \\ arundhatis5@rediffmail.com \\ www.peertechz.com
}

Keywords: Cisplatin; DNA repair enzymes; Metabolic enzymes; Nephrotoxicity; OCT; Polymorphisms

\author{
Review Article
}

\section{Genetic Polymorphisms and Cisplatin- Related Nephrotoxicity}

\section{Introduction}

Cis- diamminedichloroplatinum (cisplatin) is one of the most commonly used present day chemotherapeutic agents. It is used to treat a wide range of cancers including head and neck, lung, gastrointestinal tract, ovarian and genitourinary cancers. However, dose- limiting toxicity is often associated with cisplatin. It is known that cisplatin works more effectively with dose escalation, but significant risk for nephrotoxicity is often associated with higher doses [1].

Recovery of renal function occurs over a period of 2-4 weeks, although lack of recovery can also take place [2]. Kidney accumulates cisplatin in much higher concentration in comparison to other organs and is the major route of its excretion [3]. Five times higher cisplatin concentration was observed in proximal tubular epithelial cells in comparison to serum [4]. Highest accumulation of cisplatin occurs in S3 segment of proximal tubule followed by the distal collecting tubule and the $\mathrm{S} 1$ segment of proximal tubule [5]. Cisplatin nephrotoxicity may be presented in various ways of which the most serious presentation is acute kidney injury, which occurs in $20-30 \%$ of patients despite hyperhydration and forced Diuresis [6].

Cisplatin forms DNA cross- links in rapidly dividing tumour cells leading to apoptosis. At the same time it kills other normally dividing cells also and exerts toxic effects. Since proximal tubular cells are non- dividing it is proposed that cisplatin nephrotoxicity takes place by different mechanism not by forming DNA- adducts [7] rather by formation of nephrotoxins.

In brief, cisplatin enters the cell by both active transport and passive diffusion; however, transport- mediated uptake is the major intake mechanism in renal cells [3]. Two different membrane transporters have been identified which mediate in renal uptake of cisplatin, e.g., organic cation transporter 2 (OCT2) and copper transporter (Ctr1). Both OCT2 and Ctr1 are highly expressed in kidney and transport cisplatin in basolateral to apical direction $[2,8]$.
Conversion of cisplatin to nephrotoxin starts with the formation of platinum- glutathione conjugates (Pt- GSH) with the activity of GSH- transferase. This conjugate is then transported out of the cell [7] probably by the action of efflux pump protein [1]. It is then metabolized on cell surface through $\gamma$-glutamyl transpeptidase (GGT) expressed on the surface of the proximal tubular cells to form platinum- cysteinyl- glycine conjugate, then to platinumcysteine conjugate by another cell surface protein aminopeptidase $\mathrm{N}$. Platinum- cysteine conjugate then enters the cell and converted to highly reactive thiol with the activity of cysteine $S$-conjugate $\beta$-lyase, an intracellular enzyme [3,7]. Reactive thiol then interacts with the essential intracellular proteins which cause toxicity [7]

Nephrotoxins cause proximal cell injury, which leads to nephrotoxicity involving multiple pathways. While higher doses of cisplatin induce necrosis, a lower concentration induces apoptotic death of these cells [9]. Both nuclear and mitochondrial DNA damage, oxidative stress (caused due to increased free- radical production and decreased antioxidant production), inhibition of protein synthesis, mitochondrial dysfunction, a series of inflammatory changes, fibrogenesis etc. are the probable mechanism of renal cell injury $[3,10]$.

Considerable inter- individual differences exist in platinum drug- related toxicity. While some individuals undergoing treatment may show toxic effect for a particular regimen, others may not, and also the grade of toxicity can vary from mild to severe. In general several factors may be responsible for differential treatment outcome for the same medication. They can be categorized as physiological factors like age, sex, disease state, circadian rhythm, health status, or environmental factors like exposure to carcinogens, tobacco smoke, alcohol, co-medication or dietary constituents etc., and genetic factors [11]. Ethnicity may also account for drug-response variability [12]. While effects of non- genetic factors on drug response may be transient, effects of genetic factors may be stable as they generally lead to permanent changes in proteins those are involved in drug 
transport, drug disposition, and thus can be considered as major source of individual variability in drug response [11]. It is estimated that genetic variations may be responsible for $20-95 \%$ of the variability in therapeutic response and toxic effects [13]. Therefore, identifying genetic polymorphisms associated with adverse- drug reactions will significantly contribute to improve present day chemotherapeutic management.

\section{Genetic Polymorphisms and Nephrotoxicity \\ Genetic polymorphisms of transporters}

Members of solute carrier (SLC) super family play important role in absorption and excretion of drugs and xenobiotics in intestine, liver and kidney [14]. The SLC22 subfamily has three organic cation exporters OCT1, OCT2 and OCT3. These exporters are involved in the translocation of exo- and endogenous compounds across the epithelial membrane and help in detoxification of a wide range of xenobiotics [15]. While OCT1, encoded by SLC22A1 is the main isoform in the liver, OCT2 (SLC22A2) is the main OCT in kidney, and OCT3 (SLC22A3) is expressed widely, especially in the placenta [3]. OCT2 are expressed primarily on the basolateral membrane of the proximal tubule epithelium in the kidney [16]. Fillipsky et al. [17] found that the cisplatin- induced DNA damage in kidneys is dependent on OCT- mediated renal tubular transport. It was observed that patients having A270S (rs316019) variant for OCT2 displayed protection from nephrotoxicity in patients treated with cisplatin [17]. This variation is caused by a $\mathrm{G}>\mathrm{A}$ substitution at the 808 position of the SLC22A2 gene [16]. Iwata et al. [18] found that $808 \mathrm{G}>\mathrm{T}$ single nucleotide polymorphism (SNP) in OCT2 ameliorated cisplatin induced nephrotoxicity without altering disposition. Thus OCT2 genetic variants(s) may influence cisplatin- related nephrotoxic outcome. Cisplatin has not been established as a substrate for OCT1 or OCT3 [16].

In kidney while cisplatin is taken up by OCT, it is secreted into the lumen via other transporters situated at the brush border membrane of renal proximal tubule including multidrug and toxin extrusion 1 (MATE1) [16], a mammalian orthologue of the MATE family conferring multidrug resistance in bacteria [19]. MATE1 is encoded by SLC47A [18,20]. However, merely a few studies have been carried out to find a link between its polymorphisms and nephrotoxicity risk. Iwata et al. [18] reported no link between rs2289669 G>A polymorphism of MATE1 and cisplatin- related toxicity. For other multidrug and toxin extrusion transporter, MATE- 2, encoded by SLC47A2 and its two additional isoforms, MATE 2-K and MATE 2-B, cisplatin- induced toxicity is not established in the literature [16].

Other groups of membrane- transport proteins include copper transporter proteins (CTRs) those are responsible for maintenance of cellular level of copper [16]. CTR1, encoded by SLC31A1 mediates the initial influx of cisplatin [21]. One genetic variant of CTR1, rs $10981694 \mathrm{~A}>\mathrm{C}$, was found to be associated with cisplatin induced severe toxicity in non- small cell lung cancer (NSCLC) [22].

Transporters like P-type ATPases, e.g., ATP7A and ATP 7B are involved in removal of $\mathrm{Cu}^{2+}$ from the cells and have been shown to modulate accumulation of cisplatin into cells [23,24]. FukushimaUesaka et al. [25] assumed from their experiments in Japanese lung cancer patients that polymorphisms of ATP7A may influence the onset of various platinum drug- related toxicities.

Further, genetic variants of ATP binding cassette family proteins or $\mathrm{ABC}$ transporters may be determinant of overall toxicity in NSCLC patients receiving irinotecan plus cisplatin chemotherapy [26]. Other $\mathrm{ABC}$ proteins, e.g., $\mathrm{ABCC} 4$ which probably contributes in platinum excretion, and $\mathrm{ABCC}$, which promotes efflux of platinum compounds [16], can be molecule of interest in cislatin- related toxicity studies.

Considering the important role of above transporters related in cisplatin accumulation, it seems that their genetic variants can be important candidates for association studies with cisplatin- related nephrotoxicity.

\section{Genetic polymorphisms of DNA repair genes}

The major DNA lesions induced by cisplatin are intrastrand DNA crosslinks, those are recognized by nucleotide excision repair (NER) pathway [27]. The excision repair cross- complementation group 1 (ERCC1) protein, a member of NER pathway is involved in excision of damaged DNA along with other proteins [28,29] and thus can influence the sensitivity to cisplatin therapy. It can be expected that reduced DNA repair (NER) capacity may result in tumors that are more susceptible to cisplatin chemotherapy. Absence or low level of ERCC1 was found to be beneficial for cisplatin-based chemotherapy in non-small cell lung cancer [30] or testicular germ cell tumors [27]. It was observed that variant allele ERCC1 8092C/A was associated with significantly improved overall survival and progression-free survival in esophageal cancer patients treated with cisplatin [31]. Genetic variants of ERCC1 can therefore modulate DNA repair capacity and may influence the removal of platinum- DNA adducts. Khrunin et al. [32] studied patients of epithelial ovarian cancer treated with cisplatin based regimen. They reported a higher risk of nephrotoxicity in patients who were heterozygous for ERCC1 19007 T/C and 8092 C/A genotypes. In another study Tzvetkov et al. [33] observed in cisplatin- treated patients that homozygous carriers of the 8092A allele of ERCC1 was not related to any change in estimated glomerular filtration rate (eGFR), while it was decreased in C allele carriers. Again T allele carriers of Asn118Asn of ERCC1 were found to be associated with decreased eGFR, not homozygous $\mathrm{C}$ alleles. They concluded that genetic polymorphisms in ERCC1 may be valuable predictors of cisplatin-induced nephrotoxicity. Variants of another DNA excision repair protein xeroderma pigmentosum group D (XPD), XPD Asp312Asn, XPD Lys751Gln those are associated with decreased lymphocyte mRNA levels were found to be linked with cisplatin efficacy [31]. However, neither XPD Lys751Gln nor ERCC1 C8092A, 19007T>C were found to influence the occurrence of platinum- related grade $\geq 2$ nephrotoxicity in the study of Erculj et al. [34] in malignant mesothelioma patients.

eIF3a is the largest subunit of eukaryotic translation initiation factor 3 (eIF3) and is over expressed in many malignancies [35]. It has been suggested that it is an upstream gene of nucleotide excision repair (NER) pathway which is involved in platinum response. Xu et al. [35] studied correlation between eIF3 $\alpha$ polymorphisms and platinum- related toxicity in NSCLC patients from Chinese Han 
population treated with cisplatin and carboplatin- based regimens. They observed that $\mathrm{T}$ allele of $e$ IF $3 \alpha$ Arg803Lys C $>\mathrm{T}$ polymorphism imparted better tolerance to nephrotoxicity.

Zhang et al. [36] studied SNPs of nucleotide excision repair pathway genes for association with toxicities of platinum- based (cisplatin or carboplatin) chemotherapy in NSCLC patients. They found that MMS 19L genetic polymorphism G811A was associated with all grade of creatinine increase.

\section{Genetic polymorphisms of metabolic enzymes}

Glutathione S- transferases (GSTs) are phase II metabolic enzymes which catalyze conjugation of glutathione (GSH) to a wide variety of compounds rendering them more water soluble [37] and facilitating their excretion. Human GSTs constitute a multigene family and the genes are polymorphic either due to single nucleotide polymorphisms (SNPs) or due to deletions [38]. This family has seven classes among which GSTT1 and GSTM1 are known to have null polymorphisms or gene deletion. This polymorphism in homozygous condition abolishes enzymatic activity and reduces their detoxification properly. GST enzymes catalyze glutathione conjugation to platinum compounds also and may be involved in detoxification process of platinum drugs $[39,40]$. Barahmani et al. [39] studied GSTT1 and GSTM1 null polymorphisms as markers for toxicity in pediatric medulloblastoma patients. They found that patients with GSTM1 null genotype experienced more frequent but statistically insignificant toxicity compared with patients with the GSTM1 non- null genotype. In combined analysis it was found that patients with at least one null genotype had significantly higher risk for any $\geq 3$ toxicity. Khrunin et al. [41] observed higher risk of GSTT1 null genotype for nephrotoxicity in Yakut ovarian cancer patients receiving cisplatin- based chemotherapy whereas Russian ovarian cancer patients with ERCC1 heterozygous genotype had higher risk for nephrotoxicity.

Based on the above information extracted from the available literature, it can be concluded that the genetic signature of an individual may be responsible for cisplatin- based nephrotoxic outcome and can be exploited as predictive tool for such incidences. They will help in identifying individuals at- risk prior to medication, and in determining drug, dose and duration of the treatment appropriate for a particular individual. Thus drug- toxicity might be reduced without compromising its efficacy. Considering the importance of genetic polymorphisms in this area, variants of genes involved in other mechanisms of renal cell injury, e.g., oxidative stress, inflammatory changes etc. can be studied for cisplatin- and other platinum drug- related nephrotoxicity.

\section{References}

1. Hanigan MH, Devarajan P (2003) Cisplatin nephrotoxicity: molecular mechanisms. Cancer Ther 1: 47-61.

2. Miller RP, Tadagavadi RK, Ramesh G, Reeves WB (2010) Mechanisms of Cisplatin neurotoxicity. Toxins 2: 2490-2518.

3. Yao X, Panichpisal K, Kurtzman N, Nugent K (2007) Cisplatin nephrotoxicity: A review. Am J Med Sci 334: 115-124.

4. Kuhlmann MK, Burkhardt G, Kohler H (1997) Insights into potential cellular mechanisms of cisplatin nephrotoxicity and their clinical application. Nephrol Dial Transplant 12: 2478-2480.

5. Kroning R, Lichtenstein AK, Nagami GT (2000) Sulfur-contain-ing amino acids decrease cisplatin cytotoxicity and uptake in renal tubule epithelial cell lines. Cancer Chemother Pharmacol 45: 43-49.

6. Hartmann JT, Kollmannsberger C, Kanz L, Bokemeyer C (1999) Platinum organ toxicity and possible prevention in patients with testicular cancer. Int J Cancer 83: 866-869.

7. Zhang L, Hanigan MH (2003) Role of cysteine S-conjugate $\beta$-lyase in the metabolism of cisplatin. J Pharmacol Exp Ther 306: 988-994.

8. Pabla N, Murphy RF, Liu K, Dong Z (2009) The copper transporter Ctr1 contributes to Cisplatin uptake by renal tubular cells during Cisplatin neurotoxicity. Am J Physiol Renal Physiol 296: F505-F511.

9. Lieberthal W, Triaca V, Levine J (1996) Mechanisms of death induced by cisplatin in proximal tubular epithelial cells: apoptosis vs. necrosis. Am J Physiol 270: F700-708.

10. Ludwig T, Riethmuller C, Gekle M, Schwerdt G, Oberleithner H (2004) Nephrotoxicity of platinum complexes is related to basolateral organic cation transport. Kidney Int 66: 196-202.

11. Ma Q, Lu AY (2011) Pharmacogenetics, pharmacogenomics, and individualized medicine. Pharmacol Rev 63: 437-459.

12. Yasuda SU, Zhang L, Huang S-M (2008) The role of ethnicity in variability in response to drugs: focus on clinical pharmacology studies. Clin Pharmacol Ther 84: 417- 423.

13. Kalow W, Tang BK, Endrenyi I (1998) Hypothesis: comparisons of inter- and intra-individual variations can substitute for twin studies in drug research. Pharmacogenetics 8: 283-289.

14. Burger H, Zoumaro-Djayoon A, Boersma AWM, Boersma J, Berns EMJJ, et al. (2010) Differential transport of platinum compounds by the human organic cation transporter hOCT2 (hSLC22A2). Br J Pharmacol 159: 898-908.

15. Koepsell H, Endou H (2004) The SLC22 drug transporter family. Pflugers Arch 447: 666-676.

16. Sprowl JA, Ness RA, Sparreboom A (2013) Polymorphic transporters and platinum pharmacodynamics. Drug Metab Pharmacokinet 28: 19-27.

17. Filipski KK, Mathijssen RH, Mikkelsen TS, Schinkel AH, Sparreboom A (2009) Contribution of organic cation transporter 2 (OCT2) to cisplatininduced nephrotoxicity. Clin Pharmacol Ther 86: 396-402.

18. Iwata K, Aizawa K, Kamitsu S, Jingami S, Fukunaga E, et al. (2012) Effects of genetic variants in SLC22A2 organic cation transporter 2 and SLC47A1 multidrug and toxin extrusion 1 transporter on cisplatin- induced adverse events. Clin Exp Nephrol 16: 843-851.

19. Otsuka M, Matsumoto T, Morimoto R, Arioka S, Omote H, et al. (2005) A human transporter protein that mediates the final excretion step for toxic organic cations. Proc Natl Acad Sci U S A 102: 17923-17928.

20. Motohasi H, Inui K-I (2013) Organic cation transporter OCTs (SLC22) and MATEs (SLC47) in the human kidney. AAPS J 15: 581-588.

21. Larson CA, Blair BG, Safaei R, Howell SB (2009) The role of the mammalian copper transporter 1 in the cellular accumulation of platinum-based drugs. Mol Pharmacol 75: 324-330.

22. Xu X, Ren H, Zhou B, Zhao Y, Yuan R, et al. (2012) Prediction of copper transport protein 1 (CTR1) genotype on severe cisplatin induced toxicity in non-small cell lung cancer (NSCLC) patients. Lung Cancer 77: 438-442.

23. Komatsu M, Sumizawa T, Mutoh M, Chen ZS, Terada K, et al. (2000) Coppertransporting P-type adenosine triphosphatase (ATP7B) is associated with cisplatin resistance. Cancer Res 60: 1312-1316.

24. Samimi G, Katano K, Holzer AK, Safaei R, Howell SB (2004) Modulation of the cellular pharmacology of cisplatin and its analogs by the copper exporters ATP7A and ATP7B. Mol Pharmacol 66: 5-32. 
25. Fukushima-Uesaka H, Saito $Y$, Maekawa K, Kurose K, Sugiyama E, et al. (2009) Genetic polymorphisms of copper- and platinum drug-efflux transporters ATP7A and ATP7B in Japanese cancer patients. Drug Metab Pharmacokinet 24: 565-574.

26. Han B, Gao G, Wu W, Gao Z, Zhao X, et al. (2011) Association of ABCC2 polymorphisms with platinum-based chemotherapy response and severe toxicity in non- small cell lung cancer patients. Lung Cancer 72: 238-243.

27. Mendoza J, Martinez J, Hernandez C, Perez-Montiel D, Castro1 C, et al (2013) Association between ERCC1 and XPA expression and polymorphisms and the response to cisplatin in testicular germ cell tumours. $\mathrm{Br} \mathrm{J}$ Cancer 109: 68-75.

28. Wood RD, Mitchell M, Lindahl T (2005) Human DNA repair genes, 2005 Mutat Res 577: 275-283.

29. Leibeling D, Laspe P, Emmert S (2006) Nucleotide excision repair and cancer. J Mol Histol 37: 225-238.

30. Olaussen Ka, Fouret $P$, Kroemer G (2007) ERCC1-specific immunostaining in non-small-cell lung cancer. N Engl J Med 357: 1559-1561.

31. Bradbury PA, Kulke MH, Heist RS, Zhou W, Ma C, et al. (2009) Cisplatin pharmacogenetics, DNA repair polymorphisms, and esophageal cancer outcomes. Pharmacogenet Genomics 19: 613-625.

32. Khrunin AV, Moisseev A, Gorbunova V, Limborska S (2010) Genetic polymorphisms and the efficacy and toxicity of cisplatin-based chemotherapy in ovarian cancer patients. Pharmacogenomics J 10: 54-61.

33. Tzvetkov MV, Behrens G, O’Brien VP, Hohloch K, Brockmoller J, et al. (2011) Pharmacogenetic analyses of cisplatin-induced nephrotoxicity indicate a renoprotective effect of ERCC1 polymorphisms. Pharmacogenomics 12: 1417-1427.
34. Erculj N, Kovac V, Hmeljak J, Dolzan V (2011) The influence of platinum pathway polymorphisms on the outcome in patients with malignant mesothelioma. Ann Oncol 23: 961-967.

35. Xu X, Han L, Duan L, Zhao Y, Yang H, et al. (2012) Association between elF3a polymorphism and severe toxicity caused by platinum-based chemotherapy in non-small cell lung cancer patients. Br J Clin Pharmacol 75: 516-523.

36. Zhang L, Gao G, Li X, Ren S, Li A, et al. (2012) Association between single nucleotide polymorphisms (SNPs) and toxicity of advanced non-small-cell lung cancer patients treated with chemotherapy. PLoS ONE 7: e48350.

37. Hayes JD, Pulford DJ (1995) The glutathione S-transferase supergene family: regulation of GST and the contribution of the isoenzymes to cancer chemoprotection and drug resistance. Crit Rev Biochem Mol Biol 30: 445600.

38. Ekhart C, Rodenhuis S, Smits PHM, Beijnen JH, Huitema ADR (2009) An overview of the relations between polymorphisms in drug metabolizing enzymes and drug transporters and survival after cancer drug treatment. Cancer Treat Rev 35: 18-31.

39. Barahmani N, Carpentieri S, Li XN, Wang T, Cao Y, et al (2009) Glutathione S-transferase M1 and T1 polymorphisms may predict adverse effects after therapy in children with medulloblastoma. Neuro Oncol 11: 292-300.

40. Moyer AM, Sun Z, Batzler AJ, Li L, Schaid DJ, et al. (2010) Glutathione pathway genetic polymorphisms and lung cancer survival after platinumbased chemotherapy. Cancer Epidemiol Biomarkers Prev 19: 811-821.

41. Khrunin A, Ivanova F, Moisseev A, Khokhrin D, Sleptsova Y, et al. (2012) Pharmacogenomics of cisplatin-based chemotherapy in ovarian cancer patients of different ethnic origins. Pharmacogenomics 13: 171-178. 